\title{
Childhood abuse and neglect and insecure attachment states of mind in adulthood: Prospective, longitudinal evidence from a high-risk sample
}

\author{
K. LEE RABY, ${ }^{a}$ MADELYN H. LABELLA, ${ }^{b}$ JODI MARTIN,${ }^{c}$ ELIZABETH A. CARLSON, ${ }^{b}$ AND \\ GLENN I. ROISMAN ${ }^{b}$ \\ ${ }^{a}$ University of Utah; ${ }^{b}$ University of Minnesota; and ${ }^{c}$ York University
}

\begin{abstract}
The present report used data from the Minnesota Longitudinal Study of Risk and Adaptation to investigate the factor structure and childhood abuse and/or neglect related antecedents of adults' attachment states of mind in a high-risk sample. Adult Attachment Interviews (AAIs) were collected when participants were age 26 years $(N=164)$ and Current Relationship Interviews (CRIs) were collected from participants $(N=116)$ and their romantic partners when target participants were between ages 20 and 28 years $(M=25.3$ years). For both the AAI and the CRI, exploratory factor analyses revealed that (a) attachment state of mind scales loaded on two weakly correlated dimensions reflecting dismissing and preoccupied states of mind and (b) ratings of unresolved discourse loaded on the same factor as indicators of preoccupied states of mind. Experiencing any subtype of abuse and/or neglect, especially during multiple developmental periods, and experiencing multiple subtypes of abuse and/or neglect during childhood were associated with risk for preoccupied (but not dismissing) AAI states of mind regarding childhood relationships with caregivers. Analyses focused on the particular subtypes, and perpetrators indicated that the predictive significance of childhood abuse/neglect for adult's AAI preoccupied states of mind was specific to experiences of abuse (but not neglect) perpetrated by primary caregivers. In addition, experiencing chronic or multiple subtypes of childhood abuse and/or neglect increased risk for dismissing (but not preoccupied) CRI states of mind regarding adult romantic partners.
\end{abstract}

A foundational principle of developmental psychopathology is that research focused on atypical populations and experiences can yield insights regarding basic developmental processes, including the origins of individual differences in attachment relationships (Cicchetti, 1984; Sroufe, 1990). Because experiences of abuse and neglect represent a failure to provide the child with "the average expectable environment" (Cicchetti \& Valentino, 2006), children who have experienced these types of adverse caregiving have received substantial research attention from attachment scholars. Early research in this area demonstrated that children do form attachments to maltreating caregivers (e.g., Rajecki, Lamb, \& Obmascher, 1978); however, the quality of the attachment relationship is often severely compromised. Specifically, early studies demonstrated that experiences of abuse and neglect confer risk for insecure (Egeland \& Sroufe, 1981) and, in par-

This project was supported by Social Sciences and Humanities Research Council of Canada Postdoctoral Fellowship Award 756-2014-0109 (to J.M.) and by National Institute on Aging Grant R01 AG039453 (to J.A.S.) to support current assessments of the Minnesota Longitudinal Study of Risk and Adaptation.

Address correspondence and reprint requests to: Lee Raby, Department of Psychology, University of Utah, 380 South 1530 East, Salt Lake City, UT 84112; E-mail: lee.raby @ psych.utah.edu; or Glenn I. Roisman, Institute of Child Development, University of Minnesota, 51 East River Road, Minneapolis, MN 55455; E-mail: roism001@umn.edu. ticular, disorganized infant-caregiver attachment relationships (Carlson, Cicchetti, Barnett, \& Braunwald, 1989). Such findings have been well replicated (for a meta-analysis, see Cyr, Euser, Bakermans-Kranenburg, \& van IJzendoorn, 2010).

Because much of this work focuses on early childhood, less is known about whether the consequences of childhood abuse and neglect for attachment quality persist into adulthood. A widely used and well-validated assessment of attachment representations during adulthood is the Adult Attachment Interview (AAI; Hesse, 2008), an hour-long, semistructured interview regarding participants' childhood caregiving experiences. The coding system for the AAI focuses on adults' styles of discourse during the interview, as these discourse strategies are believed to reflect adults' mental representations or "states of mind" regarding childhood attachment relationships. Although there is a sizable body of literature examining whether child maltreatment is a risk factor for insecure attachment states of mind during adolescence and adulthood, nearly all such studies have relied on individuals' retrospective selfreports of experiences of abuse and neglect during childhood (Bailey, Moran, \& Pederson, 2007; Berthelot et al., 2015; Cloitre, Stovall-McClough, Zorbas, \& Charuvastra, 2008; Hughes, Turton, Hopper, McGauley, \& Fonagy, 2004; Jacobvitz, Leon, \& Hazen, 2006; Lyons-Ruth, Yellin, Melnick, \& Atwood, 2003; Madigan, Vaillancourt, McKibbon, \& Be- 
noit, 2012; Pierrehumbert et al., 2009; Riggs \& Jacobvitz, 2002; Stalker \& Davies, 1998; Stovall-McClough \& Cloitre, 2006; Taylor-Seehafer, Jacobvitz, \& Steiker, 2008; Zajac \& Kobak, 2009). Retrospective assessment is known to be problematic in general due to biases in memory and self-presentation (Greenhoot, 2011). Retrospective reports of maltreatment experiences in particular may be especially vulnerable to distortion because of the desire to protect caregivers from social stigma and differential interpretation of experiences of abuse and neglect, especially for incidents that are less severe. For example, drawing on data from the Minnesota Longitudinal Study of Risk and Adaptation (MLSRA), Shaffer, Huston, and Egeland (2008) demonstrated that only half of the adults with prospectively documented histories of child maltreatment retrospectively reported being abused or neglected during childhood (see Widom, Raphael, \& DuMont, 2004).

A number of other methodological issues complicate the few investigations that have combined AAI data with prospectively gathered information about individuals' experiences of abuse and neglect. Weinfield, Sroufe, and Egeland (2000) and Weinfield, Whaley, and Egeland (2004), using data from the same sample used in the present investigation, examined whether experiencing maltreatment predicted changes in overall attachment security or insecurity between infancy and late adolescence. However, these studies did not investigate direct associations between experiences of childhood abuse and neglect and attachment states of mind during adulthood. In a separate sample, Van Hoof, Van Lang, Speekenbrink, van IJzendoorn, and Vermeiren (2015) gathered information about participants' experiences of childhood sexual abuse from multiple, objective informants; however, the generalizability of the results are limited by the fact that information about experiences of physical abuse or neglect was not included, the sample size was relatively small $(N=21$ reporting childhood sexual abuse), and participants were all adolescents (aged 12 to 20 years) recruited from outpatient clinics. Finally, Beckwith, Cohen, and Hamilton (1999) investigated attachment states of mind in adolescents who had been followed prospectively following preterm birth. Parent-reported negative life events (including physical and sexual abuse) were associated with preoccupied states of mind, but only seven participants ( $8 \%$ of the total sample) were identified as having been abused, which precluded adequately powered tests of the associations between experiences of abuse and subsequent AAI states of mind.

Roisman et al. (2017 [this issue]) is the first large-sample investigation of the maltreatment-related correlates of attachment states of mind to use objective measures of individuals' experiences of abuse and neglect during childhood and adolescence. Within that sample, experiencing maltreatment, especially during multiple developmental periods, was associated with more dismissing and more preoccupied states of mind. In addition, experiencing maltreatment perpetrated by a mother figure and experiencing physical and/or sexual abuse predicted more preoccupied states of mind. Overall, these findings build on prior studies of maltreatment and attachment outcomes during early childhood by providing evidence that experiencing childhood maltreatment may have lasting consequences for individuals' attachment representations. However, because the Roisman et al. (2017 [this issue]) study focused only on AAI outcomes in a sample of adolescents, it remains unclear whether the predictive significance of childhood abuse and neglect for attachment states of mind persists into adulthood.

The primary goal of the present study was to investigate, for the first time using prospective, longitudinal data, whether experiencing abuse and/or neglect during childhood has long-term predictive significance for adults' attachment states of mind as assessed by the AAI. We further sought to extend previous research by examining whether childhood abuse and/or neglect also confer risk for adults' attachment representations of current romantic partners as assessed by the Current Relationship Interview (CRI; Crowell \& Owens, 1996). The CRI is an adaptation of the AAI protocol and coding system designed to assess an adult's discourse and representations of attachment-relevant experiences with his or her current romantic partner. According to the prototype hypothesis (Owens et al., 1995), children's early relationships with caregivers are internalized as states of mind regarding childhood caregiving experiences, which in turn serve as a template for adults' mental representations of other close relationships, including those with romantic partners. Although prior investigations of the concordance of adults' AAI and CRI attachment states of mind have yielded mixed results (e.g., Haydon, Collins, Salvatore, Simpson, \& Roisman, 2012; Owens et al., 1995), the validity of CRI romantic attachment representations has been supported by evidence of their associations with normative variation in earlier parent-child relationship experiences (Grossmann, Grossmann, \& Kindler, 2006; Haydon et al., 2012). The potential predictive significance of atypical and adverse caregiving experiences, including childhood abuse and neglect, for the development of adults' representations of their romantic partners has not yet been examined.

In addition to investigating the antecedents of adults' attachment states of mind in experiences of childhood abuse and neglect, we also explored the factor structure of adults' attachment states as assessed by both the AAI and the CRI. Over the last 15 years, a number of factor analytic studies, notably including investigations based on large samples, have provided consistent evidence that the ratings of individuals' AAI states of mind are accounted for by two underlying factors (e.g., Haltigan, Roisman, \& Haydon, 2014; Roisman, Fraley, \& Belsky, 2007). The first of these factors reflects the degree to which individuals minimize discussion of their childhood attachment-related experiences versus freely reflect on and discuss the significance of those experiences (i.e., dismissing states of mind). The second captures the degree to which adults become emotionally enmeshed when discussing previous attachment-related experiences or psychologically confused when discussing experiences of loss 
or abuse (i.e., preoccupied states of mind). These factor analytic findings differ from the traditional conceptualization of the AAI factor structure in two key ways. First, in contrast to the assumption embedded within the categorical AAI coding system (Main \& Goldwyn, 1998) that dismissing and preoccupied states of mind are incompatible, the empirically derived dismissing and preoccupied state of mind dimensions are only modestly correlated. Second, in prior studies, indicators of unresolved loss and abuse have consistently loaded on the same factor as indicators of preoccupation, which suggests that unresolved and preoccupied discourse reflect a single construct.

Although the factor structure of the AAI described above has been replicated consistently, nearly all the relevant studies have been based on normative- or low-risk samples. The only two studies to examine the factor structure of the AAI state of mind scales within high-risk samples were limited by the fact that the analyses combined subsamples of participants characterized by clinical characteristics (i.e., classified as having borderline personality disorder or reported nonsuicidal selfinjurious behaviors) with low-risk participants (Macfie, Swan, Fitzpatrick, Watkins, \& Rivas, 2014; Martin, Bureau, et al., 2017 [this issue]). As a result, it remains an open question as to whether this two-factor model accurately characterizes individual differences in AAI states of mind within highrisk populations, such as individuals with histories of poverty. Van IJzendoorn and Bakermans-Kranenburg (2014), for example, argued that the question of whether unresolved and preoccupied discourse represent a single psychological construct would be best addressed within high-risk samples in which these forms of insecurity are more prevalent (see Roisman, Fraley, \& Booth-LaForce, 2014).

In contrast to the AAI, the factor structure of adults' CRI romantic attachment states of mind has not received much empirical attention. The only empirical examination of the factor structure of the CRI state of mind rating scales involved a normative-risk sample of elderly couples (Waldinger, Cohen, Schulz, \& Crowell, 2015). In addition, although this factor analysis identified only a single factor they claimed represented security versus insecurity, the analysis excluded several of the state of mind ratings, including ratings related to adults' preoccupied and unresolved discourse during the CRI.

In sum, the two goals of the present study were to investigate (a) the factor structure and (b) the childhood abuse and/or neglect related antecedents of attachment states of mind during adulthood in a higher risk sample. Specifically, we drew on data from the MLSRA (Sroufe, Egeland, Carlson, \& Collins, 2005), a long-term investigation of approximately 180 individuals who were born into poverty and have been followed from birth into adulthood. Within the MLSRA, information about participants' experiences of abuse and neglect was gathered prospectively from infancy to late adolescence, and AAIs and CRIs were collected during young adulthood. The current study builds on prior investigations with this sample, which have focused on the antecedents of AAI and CRI security within the normative range of caregiving experiences (i.e., sensitive caregiving), as well as stability and change in attachment security from infancy to young adulthood (e.g., Haydon et al., 2012; Raby, Cicchetti, Carlson, Egeland, \& Collins, 2013; Roisman, Madsen, Hennighausen, Sroufe, \& Collins, 2001; Weinfield et al., 2004) by directly examining longitudinal associations between participants' childhood experiences of abuse and/or neglect and later dismissing and preoccupied attachment states of mind during young adulthood.

\section{Method}

\section{Participants}

Between 1975 and 1977, pregnant mothers who were living below the poverty line and receiving prenatal services through the local health department in Minneapolis, Minnesota, were recruited for participation in the MLSRA. At the time of their child's birth, $48 \%$ of the mothers were teenagers, $65 \%$ were single, and $42 \%$ had completed less than a high school education. The current subsamples consisted of 164 participants (49\% female) who completed an AAI at age 26 years and 116 participants (48\% female) who completed a CRI during young adulthood. These two subsamples overlapped, as 114 of the participants who completed a CRI also completed an AAI at age 26 years. These subsamples did not significantly differ from those in the original sample who were not included in these analyses with respect to maternal age or marital status at the time of the child's birth. However, participants who completed the AAI and participants who completed the CRI had mothers with more years of education at the time of the child's birth than participants who did not complete these assessments, AAI: $M=11.9, S D$ $=1.8$ versus $M=11.3, S D=1.8, t(256)=2.7, p<.01, d=$ 0.33; CRI: $M=12.0, S D=1.9$ versus $M=11.5, S D=1.7$, $t(256)=2.3, p=.02, d=0.28$. Average levels of maternal education in the current subsamples were still equal to or less than a high school education, consistent with a highrisk cohort. In these subsamples, approximately $68 \%$ of the participants were White/non-Hispanic, $18 \%$ were multiracial, $11 \%$ were African American, and 3\% were Native American, Hispanic, or Asian American.

\section{Measures}

AAI. AAIs were completed with MLSRA participants at age 19 years and age 26 years. The current study focuses on data collected from the age 26 AAIs because our aim was to examine the long-term predictive significance of experiencing abuse and neglect during childhood for attachment outcomes in adulthood and because ratings for passivity of thought, a focal indicator of preoccupied states of mind, were not assigned for the age 19 AAIs (but see Martin, Raby, Labella, \& Roisman, 2017). The age 26 AAI transcripts were coded by raters who had completed reliability certification with 
Dr. Mary Main's lab. Following Main and Goldwyn's (1998) guidelines, AAI narratives were rated on a series of 9-point scales intended to assess participants' state of mind regarding childhood caregiving experiences. Consistent with the highrisk nature of the MLSRA cohort, the average rating for the participants' coherence of mind during the AAI (which is widely used as an index of overall AAI security; e.g., Raby et al., 2013) was 4.4 on a 9-point scale. Perhaps more relevant, $88 \%$ of cases reported a qualifying loss experience, with $74 \%$ of participants showing some unresolved discourse regarding their loss experiences (i.e., receiving scores higher than 1). Moreover, $38 \%$ of cases reported a relevant abuse experience, with $30 \%$ of participants showing some unresolved discourse regarding their abuse experiences.

For the exploratory factor analyses, the ratings for fear of loss and meta-cognitive processes were excluded from all analyses due to low variability within the current sample (i.e., $S D<1$ ). In addition, the coherence of transcript rating was excluded because it was empirically redundant with the coherence of mind rating $(r=.97)$. Consistent with prior research in this area (e.g., Haltigan et al., 2014; Roisman et al., 2007), cases without applicable unresolved loss and/or abuse experiences received a score of 1 for these scales (the low end of the unresolved loss and abuse scales indicating no unresolved loss and/or abuse) so that such cases could be included in the factor analysis. In addition, mother and father anger and idealization scales were averaged across all coded maternal and paternal caregiving figures. Interrater reliability (intraclass correlations [ICCs]) for all state of mind rating scales were greater than 0.65 based on a sample of 44 randomly selected cases.

CRI. The CRI was completed when participants were age 2021 years and again when participants were age 26-28 years. At both ages, participants were required to have been in a romantic relationship for at least 6 months in order to participate in the assessment. Among qualifying relationships, average relationship length was 27.6 months $(S D=21.1)$ at the time of the age 20-21 assessments and 44.9 months $(S D=$ 28.9 ) at the time of the age 26-28 assessments. Information from the two assessments was aggregated in order to maximize sample size. Information from the age 26-28 year assessment was selected when available $(n=54)$ in order to more closely parallel the timing of the age 26 AAI. Information from the age 20-21 assessment was used for an additional 33 participants who did not provide CRI data at age 26-28. The average age of the participants at the time of the selected romantic relationship assessment was 25.3 years $(S D=2.9)$. As previously reported by Haydon et al. (2012), participants from the age 20-21 and participants from the age 26-28 assessments did not differ with regard to romantic relationship perceptions or observed behavior during an interaction with their romantic partners. In addition, CRIs were completed with the opposite-sex partners of 107 participants. In order to maximize the sample size, and thereby enhance the replicability of the results, the exploratory factor analysis of the CRI ratings was completed using data from the target participants and their partners when available (combined $N$ $=223$ ). The factor structure of the CRI ratings was subsequently examined using only the ratings for the target participants as a robustness check, and results did not differ from what is reported below. Because information about childhood abuse and neglect was not available for the partners, only data for the target participants were included in analyses regarding the developmental antecedents of CRI states of mind.

CRI transcripts were coded by raters who had completed training for both the AAI and the CRI scoring procedures. AAI and CRI transcripts were coded by independent raters who were unaware of participants' ratings on the other measure. Following Crowell and Owens's (1996) guidelines, CRI narratives were rated on three sets of 9-point scales that assess: the participant's previous romantic relationship experiences and satisfaction in the current relationship, the participant's and the partner's behaviors in the relationship, and the participant's discourse style. This last set of ratings, which includes valuing intimacy, valuing independence, angry speech regarding partner, angry speech regarding others, derogation of romantic partner, derogation of attachment, idealization of the romantic partner or relationship, passivity of speech, fear of loss of partner, unresolved or disorganized discourse, and overall coherence of the transcript, was selected for the current study because these ratings are believed to reflect adults' state of mind regarding attachment in their current romantic relationship. Because ratings for derogation of romantic partner and derogation of attachment were strongly correlated ( $r$ $=.67$ ) and in order to parallel the variables from the AAI, the two derogation ratings were combined by selecting the highest derogation rating. The fear of loss rating was excluded because of low variability within the current sample (i.e., $S D<1$ ).

Interrater reliability (ICCs) was based on a sample of 69 randomly selected transcripts for the target participants and their partners from the age 20-21 and age 26-28 assessments. ICC estimates were 0.60 or greater for all ratings except idealization ( $\mathrm{ICC}=0.46$ ). Because this rating is central to judgments regarding individuals' romantic attachment states of mind, it was retained in the analyses. The factor structure of the remaining CRI ratings did not differ from what is reported below when this rating was excluded.

Adverse caregiving: Abuse and neglect. The MLSRA uses the rubric childhood experiences of adverse caregiving as an umbrella term to refer to a variety of atypical parent-child experiences that were prospectively measured in the MLSRA cohort and are believed to be harmful to children's development. The present study focused exclusively on information collected about MLSRA participants' adverse caregiving experiences of physical abuse, sexual abuse, and neglect. This information was recoded to apply contemporaneous definitions of abuse and neglect, to identify the specific perpetrator and ages of the abuse and neglect experiences, and to assess the reliability of those coding decisions. Coding criteria were 
based on definitions developed by the Centers for Disease Control and Prevention (CDC) in order to "promote consistent terminology and data collection related to child maltreatment" (Leeb, Paulozzi, Melanson, Simon, \& Arias, 2008, p. 4). The coding included (a) neglect of a child's basic physical or cognitive needs, defined as a caregiver's failure to provide adequate hygiene, shelter, clothing, medical care, supervision, or education; (b) physical abuse, defined as a caregiver's "intentional use of physical force against a child that results, or has the potential to result in, physical injury" (Leeb et al., 2008, p. 14); and (c) sexual abuse, defined as sexual contact (e.g., molestation and rape) or noncontact exploitation (e.g., intentional exposure of child to pornography) by a custodial caregiver or by a perpetrator 5 or more years older than the target child. Although the CDC criteria only addresses sexual abuse perpetrated by a caregiver, the inclusion of noncaregiving perpetrators and the use of a 5-year cutoff is consistent with other research in this area (e.g., Stoltenborgh, van IJzendoorn, Euser, \& Bakermans-Kranenburg, 2011).

These CDC definitions were supplemented by a set of more specific coding guidelines that distinguished clear indicators of physical abuse, sexual abuse, and physical/cognitive neglect from ambiguous indicators that were not sufficient for classification in isolation of other evidence. These additional guidelines were developed in consultation with MLSRA senior researchers, Minnesota state law, and available research literature (e.g., Barnett, Manly, \& Cicchetti, 1993) and are available from the first author upon request. However, the classifications of childhood experiences of abuse or neglect do not necessarily reflect criteria for maltreatment used by child protective services, which vary from state to state.

Although emotional unavailability or lack of caregiver responsiveness has proven to be an important dimension of adverse caregiving (especially for young children), with pernicious developmental consequences (National Scientific Council on the Developing Child, 2012; Sroufe et al., 2005), this dimension was not included in the current coding criteria due to insufficient information across developmental periods. Similarly, exposure to violence between caregivers and other forms of environmental violence were not included in the current set of codes. Exposure to violence between caregivers is captured by a separate variable in the MLSRA data set (e.g., Narayan, Englund, \& Egeland, 2013), and insufficient information was available to code adequately exposure to other forms of environmental violence.

Judgments regarding abuse and neglect experiences were made for participants whose records had been previously flagged as potentially ever abused or neglected $(n=139$, $52 \%$ of the original sample). For these cases, all available data collected from birth to 17.5 years (up to 25 assessments) were reviewed for information regarding caregiving quality, physical discipline, supervision, home environment, physical and sexual assault, child protective service involvement, and foster care history. Information was obtained from parentchild observations, caregiver interviews, reviews of available child protection and medical records, adolescent reports, and teacher interviews. Disclosures of childhood physical or sexual abuse during the AAI were not included in the present set of codes except in situations in which an experience of abuse was initially identified based on records through age 17.5 years, but there was insufficient detail to code the specific developmental period or perpetrator (e.g., an adolescent disclosed a history of sexual assault without specifying whether the perpetrator was a peer). In these cases, available AAIs were consulted only for clarifying information about the previously identified incident.

Coding focused on the presence or absence of physical abuse, sexual abuse, and/or neglect in each of four developmental periods (infancy: birth to 24 months; early childhood: 25 months to 5 years; middle childhood: 6-12 years; and adolescence: $13-17.5$ years). For incidents of physical and sexual abuse, coders additionally specified the perpetrator. Perpetrators included maternal caregivers (biological mothers, stepmothers, and grandmothers), paternal or father figures (biological fathers, stepfathers, adoptive fathers, and mothers' live-in boyfriends), and nonparental figures (relatives, neighbors, babysitters, and family friends). Two coders reviewed each case and demonstrated good to excellent reliability for all parameters: $\kappa$ values were between 0.80 and 0.98 for presence or absence of physical abuse, sexual abuse, and/or neglect; 0.80 and 0.84 for presence or absence of each subtype during each development period; and 0.80 and 0.98 for incidents of physical or sexual abuse by each category of perpetrator. All discrepancies were resolved by consensus.

Within the full sample of MLSRA participants $(N=267)$, 102 individuals were classified as having ever experienced physical abuse, sexual abuse, and/or neglect; 81 were coded as not having experienced abuse or neglect; and the status of 84 was deemed unclear due to missing data (see below). By developmental period, 48 individuals were classified as being abused and/or neglected in infancy (of the 211 with sufficient data to allow for confident classifications of abuse and/or neglect during this developmental period), 69 in early childhood (of the 185 with sufficient data during this developmental period), 66 in middle childhood (of the 190 with sufficient data during this developmental period), and 21 in adolescence (of the 179 with sufficient data during this developmental period).

Within the subsample of participants with age 26 AAI data $(N=164), 79$ individuals were classified as having ever experienced physical abuse, sexual abuse, and/or neglect. Among this group, $37 \%$ experienced abuse and/or neglect in infancy, $69 \%$ during early childhood, $72 \%$ during middle childhood, and $23 \%$ during adolescence (not mutually exclusive). In terms of chronicity, $36 \%$ of this group experienced abuse and/or neglect during one developmental period, $33 \%$ during two periods, $29 \%$ during three periods, and $3 \%$ during all four developmental periods. In terms of subtype, $64 \%$ of individuals with histories of abuse and/or neglect had experienced neglect, $60 \%$ had experienced physical abuse, and $42 \%$ had been sexually abused (not mutually exclusive). Approximately $50 \%$ of individuals with histories 
of abuse and/or neglect experienced one subtype, $40 \%$ experienced two subtypes, and $10 \%$ and experienced all three subtypes. Moreover, $42 \%$ of individuals with abuse and/or neglect histories experienced physical and/or sexual abuse by a father figure, $41 \%$ by a maternal figure, and $29 \%$ by a nonparent (not mutually exclusive).

In order to separate individuals who had not experienced abuse and/or neglect from those with missing data, a participant was coded as missing abuse and neglect data if (a) the participant was not coded as having been abused and/or neglected based on the available information and (b) the participant was missing two or more full assessments within any given developmental period. Within the subsample of participants with age 26 AAI data, 15 individuals were classified as missing information related to the current classification of abuse or neglect. The remaining 70 individuals comprised the nonabused/neglected group. The number of missing assessments for this group did not differ from the group of individuals who were classified as having ever experienced abuse and/or neglect $(t=-0.69, p=.49)$.

Control variables. In order to test whether the predictive significance of childhood abuse and/or neglect for adults' attachment states of mind was independent of key covariates, we included four control variables that have been used in prior research on the developmental antecedents of the AAI (Haydon, Roisman, Owen, Booth-LaForce, \& Cox, 2014; Roisman et al., 2017 [this issue]) and prior research from the MLSRA (Raby, Roisman, Simpson, Collins, \& Steele, 2015): child gender, child ethnicity, maternal education, and childhood socioeconomic status. Because most of the children in the sample were White/non-Hispanic, a binary variable was created to represent ethnicity ( $1=$ White/nonHispanic, $0=$ otherwise). Maternal education was operationalized as the number of years of education each mother had completed. This information was collected at seven assessments during childhood and adolescence ( 3 months before the child's birth, 42 months, Grades 1-3, Grade 6, and age 16 years), and the various measures were averaged to create a composite measure of maternal education. Socioeconomic status was assessed with Duncan's Socioeconomic Index, a widely used indicator of occupational ranking (Stevens $\&$ Featherman, 1981). Scores were based on the mother's occupational status, which was collected at seven assessments during childhood and adolescence (42 months, 54 months, Grades 1-3, Grade 6, and age 16 years). These various measures were averaged to create a composite measure of childhood socioeconomic status.

Missing data. Among the subsample of participants who completed an AAI at age $26(N=164)$ and the subsample of participants plus partners who completed a CRI $(N=$ 223), there was a small percentage of missing data on specific ratings scales because coders lacked sufficient information to confidently assign a rating (between $1 \%$ and $9 \%$ for AAI ratings; less than $2 \%$ for CRI ratings). As previously discussed,
$9 \%$ of cases were missing sufficient information to make a determination regarding childhood abuse and/or neglect. To address these missing data, the factor and regression analyses used full-information maximum likelihood, which produces less biased and more consistent parameter estimates than pairwise or listwise deletion for missing data (Graham, 2009). All statistical analyses were carried out using Mplus (Muthén \& Muthén, 1998-2015).

\section{Results}

Analyses are presented below in two sections. In the first, the factor structure of the AAI and the CRI state of mind scales was examined using exploratory factor analyses (EFA). In the second section, we report the predictive significance of childhood abuse and/or neglect for adults' attachment states of mind. AAI and CRI ratings were examined separately in all analyses.

\section{The factor structure of adults' attachment states of mind}

AAI attachment states of mind. The factor structure of the AAI state of mind scales was examined via EFA (maximum likelihood estimation) with an oblique rotation (direct oblimin), which allows, but does not force, factors to correlate with one another. The number of factors was selected based on examination of the scree plot and by conducting a parallel analysis, which is considered best practice for determining the number of factors to retain (Fabrigar, Wegener, MacCallum, \& Strahan, 1999). This method generates a series of reference eigenvalues based on randomly generated data with the same number of observations and variables as the original data. The eigenvalues from the parallel analysis are compared to those from the original data, and the factors in the original data with eigenvalues larger than the eigenvalues from the parallel analysis are selected for further examination.

These approaches indicated that a two-factor solution best accounted for the data (see Table 1). The first factor contained ratings used by coders to make distinctions regarding adults' dismissing states of mind about their childhood attachment experiences, including idealization of the mother, idealization of the father, and lack of recall. The second factor contained ratings used by coders to make judgments about adults' preoccupied states of mind, including passivity of thought, angry speech about the mother, and angry speech about the father. Ratings for unresolved abuse and unresolved loss also significantly loaded on the second factor. Although derogation has traditionally been assumed to be an indicator of a dismissing state of mind, this rating had a low loading on the second factor, as has been reported in other factor analyses of normative risk samples (e.g., Roisman et al., 2007). Coherence of mind nontrivially cross-loaded on both factors.

Overall, the results of the EFA were consistent with findings from the large-sample analysis of the AAI data from the Study of Early Childcare and Youth Development (Haltigan et al., 2014). As such, we created composite measures of adults' 
Table 1. Factor loadings for the exploratory factor analysis of the Adult Attachment Interview state of mind ratings

\begin{tabular}{lrr}
\hline \hline & \multicolumn{1}{c}{ I } & II \\
\hline Coherence of mind & -.79 & -.51 \\
Maternal idealization & $\mathbf{. 7 9}$ & -.25 \\
Lack of memory & $\mathbf{. 6 9}$ & -.21 \\
Paternal idealization & $\mathbf{. 5 9}$ & -.27 \\
Passivity of thought & -.14 & $\mathbf{. 7 1}$ \\
Maternal anger & -.13 & $\mathbf{. 6 4}$ \\
Unresolved abuse & -.13 & $\mathbf{. 6 0}$ \\
Paternal anger & .07 & $\mathbf{. 5 6}$ \\
Unresolved loss & -.01 & $\mathbf{. 4 9}$ \\
Overall derogation & -.01 & $\mathbf{. 4 9}$ \\
Eigenvalue & & \\
$\quad$ For data & 3.13 & 2.41 \\
From parallel analysis & 1.42 & 1.29 \\
\hline \hline
\end{tabular}

Note: $N=164$. Values in bold are the factors on which each scale loaded most strongly.

AAI dismissing and preoccupied attachment states of mind in a manner that maximized the consistency with the measures used by Haltigan et al. (2014). Specifically, highest derogation and unresolved loss were not included in the preoccupied composite because the loadings were relatively low in the Study of Early Childcare and Youth Development as well as the MLSRA, and the coherence of mind rating was not included in either composite given substantial cross-loading in both samples. This cross-loading is consistent with the role of the coherence of mind scale, which is intended to be a summary rating of adults' AAI discourse in which participants are assigned low ratings if there is evidence of either dismissing or preoccupied discourse, by definition. Thus, the AAI dismissing composites included ratings of idealization of mother, idealization of father, and lack of memory $(\alpha=0.72)$, and the AAI preoccupied composites included ratings of passivity of thought, unresolved trauma, anger toward mother, and anger toward father $(\alpha=0.69)$. There was a modest negative association between participants' AAI dismissing and preoccupied states of mind $(r=-.33, p<.001)$.

CRI attachment states of mind. The factor structure of the CRI attachment state of mind scales was examined using the same methods. Specifically, the EFA used maximum likelihood estimation and a direct oblimin rotation, and the number of factors was selected based on examination of the scree plot and by conducting a parallel analysis. These analyses revealed that both two- and three-factor solutions accounted for the data reasonably well (see Table 2). Within the two-factor solution, the first factor included the ratings involved in differentiating secure from dismissing romantic attachment states of mind, including coherence, valuing intimacy, idealization, and valuing of independence. The second factor contained ratings that reflect preoccupied romantic attachment states of mind, including passivity, anger toward partner, and anger toward others. Similar to findings with the AAI, unresolved states of mind also loaded on this second factor. Ratings for valuing independence and derogation had weak cross-loadings on both factors. The factor structure for the three-factor solution was highly similar except that (a) derogation loaded on the third factor and (b) valuing independence had low loadings on all three factors.

Because the third factor included only a single indicator, the two-factor model was selected as the most parsimonious solution. Measures of target participants' dismissing and preoccupied romantic attachment states of mind were created by averaging the relevant indicators $(\alpha=0.82$ for CRI dismissing states of mind; $\alpha=0.69$ for CRI preoccupied states of mind). Coherence and valuing intimacy were reverse-scored prior to averaging. Valuing of independence and derogation

Table 2. Factor loadings for the exploratory factor analysis of the Current Relationship Interview state of mind ratings

\begin{tabular}{|c|c|c|c|c|c|}
\hline & \multicolumn{2}{|c|}{ Two-Factor Model } & \multicolumn{3}{|c|}{ Three-Factor Model } \\
\hline & I & II & I & II & III \\
\hline Coherence of transcript & .91 & -.16 & .92 & -.22 & .06 \\
\hline Valuing intimacy & .81 & .02 & .81 & .14 & -.26 \\
\hline Idealization & -.69 & -.26 & -.68 & -.14 & -.18 \\
\hline Valuing independence & -.20 & -.15 & -.17 & -.24 & .25 \\
\hline Anger toward partner & -.01 & .71 & -.04 & .55 & .27 \\
\hline Passivity & -.09 & .70 & -.07 & .84 & -.06 \\
\hline Anger toward others & -.02 & .56 & -.03 & .42 & .27 \\
\hline Unresolved & .11 & .47 & .14 & .38 & .31 \\
\hline Overall derogation & -.19 & .30 & -.14 & .12 & .58 \\
\hline \multicolumn{6}{|l|}{ Eigenvalue } \\
\hline For data & 2.92 & 1.62 & 2.92 & 1.62 & 1.04 \\
\hline From parallel analysis & 1.33 & 1.21 & 1.33 & 1.21 & 1.13 \\
\hline
\end{tabular}

Note: $N=223$. Values in bold are the factors on which each scale loaded most strongly. 
Table 3. Correlations among abuse and neglect variables

\begin{tabular}{|c|c|c|c|c|c|c|c|c|}
\hline Variable & 1 & 2 & 3 & 4 & 5 & 6 & 7 & 8 \\
\hline 1. Abuse/neglect status & - & & & & & & & \\
\hline 2. Abuse/neglect chronicity & $.85^{* * *}$ & - & & & & & & \\
\hline 3. No. of abuse/neglect subtypes & $.86^{* * *}$ & $.90 * * *$ & - & & & & & \\
\hline 4. Neglect & $.67 * * *$ & $.72 * * *$ & $.77 * * *$ & - & & & & \\
\hline 5. Sexual abuse & $.51 * * *$ & $.47 * * *$ & $.58 * * *$ & .14 & - & & & \\
\hline 6. Physical abuse & $.64 * * *$ & $.71 * * *$ & $.77 * * *$ & $.44 * * *$ & $.16^{*}$ & - & & \\
\hline 7. Paternal abuse perpetrator & $.50 * * *$ & $.57 * * *$ & $.63 * * *$ & $.35 * * *$ & $.37 * * *$ & $.61 * * *$ & - & \\
\hline 8. Maternal abuse perpetrator & $.50 * * *$ & $.60 * * *$ & $.61 * * *$ & $.37 * * *$ & .14 & $.75 * * *$ & $.20 * *$ & - \\
\hline 9. Other abuse perpetrator & $.39 * * *$ & $.30 * * *$ & $.39 * * *$ & .09 & $.70 * * *$ & .08 & -.01 & .15 \\
\hline
\end{tabular}

Note: $N=164$.

$* p<.05 . * * p<.01 . * * * p<.001$.

were not included in the composites because the loadings were relatively low. Target participants' CRI dismissing and preoccupied states of mind were positively, but not significantly, correlated $(r=.17, p=.08)$.

\section{Predictive significance of childhood abuse and neglect for adults' attachment states of mind}

The predictive significance of children's experiences of abuse and neglect was evaluated using a set of regression analyses predicting each of the AAI and CRI state of mind dimensions. Separate analyses were conducted for five, nonindependent abuse and neglect parameters: overall classification of abuse/neglect status (binary code indicating whether individuals experienced any type of abuse or neglect during any developmental period), abuse/neglect chronicity (number of developmental periods in which individuals experienced any type of abuse and/or neglect; theoretical range $=0-4$ ), number of abuse and/or neglect subtypes ever experienced (theoretical range $=0-3$ ), specific subtypes (binary codes indicating whether individuals ever experienced neglect, sexual abuse, and/or physical abuse), and abuse perpetrator (binary codes for fathers, mothers, and/or others). These parameters are often included in investigations of the consequences of abuse and neglect for children's development (for a review, see Cicchetti, 2016), including research on AAI outcomes (Roisman et al., 2017 [this issue]).

The various abuse and neglect parameters empirically overlap to a considerable degree (see Table 3 for correlations within the AAI subsample). For each outcome, we began with an omnibus assessment of whether attachment states of mind were predicted by childhood abuse/neglect status, followed by abuse/neglect chronicity and the number of abuse/neglect subtypes. In order to examine what aspects of abuse and/or neglect are most strongly implicated in the development of adult attachment states of mind, we then attempted to decompose these more global associations by focusing on parameters that reflect specific subtypes of childhood abuse and/or neglect experiences as well as specific abuse perpetrators. For each analysis, the focal abuse and neglect variables were entered in the initial step of the regression model. Participant gender, participant ethnicity, maternal education, and family socioeconomic status were also included in the second step. Finally, the nonfocal state of mind dimension was included in a third step of the regression model to test whether the predictive significance of the various abuse and neglect experiences were unique to the attachment state of mind dimension of interest.

Descriptive statistics and zero-order correlations are presented in Table 4. AAI dismissing states of mind were uniquely associated with CRI dismissing states of mind, and AAI preoccupied states of mind were uniquely associated with CRI preoccupied states of mind. Consistent with findings from several other large samples (Haydon et al., 2014; Roisman et al., 2017 [this issue]), males scored higher on dismissing AAI states of mind than did females, and females scored higher on preoccupied AAI states of mind than did males. In addition, participants who were White/non-Hispanic had lower levels of preoccupied AAI states of mind than participants from other ethnic backgrounds.

AAI attachment states of mind. As reported in Tables 5-7, experiencing abuse and/or neglect, especially during multiple developmental periods or involving multiple subtypes, significantly increased risk for AAI preoccupied, but not dismissing, states of mind. These associations were robust to controls for participant gender, ethnicity, maternal education, childhood socioeconomic conditions, and AAI dismissing states of mind. Analyses related to the specific abuse and neglect subtypes indicated that physical abuse was associated with risk for AAI preoccupied states of mind even after controlling for gender, ethnicity, maternal education, childhood socioeconomic conditions, and AAI dismissing states of mind (see Table 8). In addition, there was a marginally significant association between experiencing sexual abuse and increased risk for AAI preoccupied states of mind; however, this association was no longer statistically significant after controlling for covariates. Neglect during childhood was not uniquely associated with increased risk for either AAI preoccupied or dismissing states of mind. Abuse perpetration 
Table 4. Correlations and descriptive statistics for AAI, CRI, and demographic variables

\begin{tabular}{|c|c|c|c|c|c|c|c|c|}
\hline Variable & 1 & 2 & 3 & 4 & 5 & 6 & 7 & 8 \\
\hline 1. AAI dismissing & - & & & & & & & \\
\hline 2. AAI preoccupied & $-.33 * * *$ & - & & & & & & \\
\hline 3. CRI dismissing & $.36^{* * *}$ & -.01 & - & & & & & \\
\hline 4. CRI preoccupied & -.07 & $.38 * * *$ & .17 & - & & & & \\
\hline 5. Gender & $-.17 *$ & $.22 * *$ & -.11 & .18 & - & & & \\
\hline 6. Ethnicity & .04 & $-.19 *$ & -.08 & -.05 & .07 & - & & \\
\hline 7. Maternal education & -.03 & -.12 & -.18 & -.02 & $-.15^{*}$ & -.11 & - & \\
\hline 8. Childhood SES & -.08 & -.06 & -.11 & -.01 & -.05 & .03 & $.59 * * *$ & - \\
\hline Mean or percentage & 3.07 & 2.19 & 4.73 & 2.43 & $49 \%$ & $68 \%$ & 12.43 & 23.50 \\
\hline$S D$ & 1.65 & 1.13 & 1.74 & 1.17 & - & - & 1.68 & 10.45 \\
\hline
\end{tabular}

Note: $N=164$ except for correlations involving CRI variables $(N=116)$. AAI, Adult Attachment Interview; CRI, Current Relationship Interview; SES, socioeconomic status. Gender was coded $1=$ female, $0=$ male; Ethnicity was coded $1=$ White/non-Hispanic, $0=$ non-White.

$* p<.05 . * * p<.01 . * * * p<.001$.

Table 5. Predicting AAI Dimensions from childhood abuse/neglect status

\begin{tabular}{|c|c|c|c|c|c|c|}
\hline & \multicolumn{3}{|c|}{ AAI Dismissing } & \multicolumn{3}{|c|}{ AAI Preoccupied } \\
\hline & $\beta$ & $p$ & $R^{2}$ & $\beta$ & $p$ & $R^{2}$ \\
\hline 1. Abuse/neglect status & 0.03 & .73 & .00 & 0.25 & $<.01$ & .06 \\
\hline 2. Abuse/neglect status & -0.01 & .95 & .04 & 0.24 & $<.01$ & .15 \\
\hline Participant gender & -0.18 & .02 & & 0.22 & $<.01$ & \\
\hline Participant ethnicity & 0.05 & .49 & & -0.20 & $<.01$ & \\
\hline Maternal education & -0.00 & .98 & & -0.08 & .38 & \\
\hline Childhood SES & -0.09 & .34 & & 0.08 & .41 & \\
\hline 3. Abuse/neglect status & 0.08 & .37 & .13 & 0.24 & $<.01$ & .24 \\
\hline Participant gender & -0.10 & .18 & & 0.17 & .02 & \\
\hline Participant ethnicity & -0.01 & .87 & & -0.18 & $<.01$ & \\
\hline Maternal education & -0.03 & .75 & & -0.08 & .35 & \\
\hline Childhood SES & -0.07 & .47 & & 0.05 & .58 & \\
\hline AAI dismissing & - & - & & -0.30 & $<.01$ & \\
\hline AAI preoccupied & -0.34 & $<.01$ & & - & - & \\
\hline
\end{tabular}

Note: $N=164$. AAI, Adult Attachment Interview; SES, socioeconomic status. For participant gender, $1=$ female, $0=$ male. For participant ethnicity, $1=$ White/non-Hispanic, $0=$ other. All models were significant at $p<.01$ except Model 1 and Model 2 for AAI dismissing ( $p=.73$ and .19 , respectively).

by a maternal or paternal caregiver (but not others) significantly increased risk for AAI preoccupied states of mind, and these associations were robust to the inclusion of covariates (see Table 9).

CRI attachment states of mind. As reported in Table 10, experiencing abuse and/or neglect was associated with a marginally significant increased risk for CRI dismissing, but not preoccupied, states of mind. This association was no longer significant after controlling for gender, ethnicity, maternal education, and childhood socioeconomic conditions. In contrast, the chronicity of childhood abuse and/or neglect was robustly associated with increased risk for CRI dismissing states of mind even after including gender, ethnicity, maternal education, childhood socioeconomic conditions, and CRI preoccupation (see Table 11). Likewise, the number of abuse and neglect subtypes was associated with increased risk for
CRI dismissing states of mind (see Table 12). This association was still significant after controlling for gender, ethnicity, maternal education, and childhood socioeconomic conditions but dropped to marginally significant ( $p=.051)$ after controlling for CRI preoccupation. Specific subtypes of abuse or neglect and abuse perpetrators were not associated with later CRI states of mind (see Tables 13-14).

\section{Discussion}

The present study examined the factor structure and childhood abuse and/or neglect related antecedents of adults' attachment states of mind within the MLSRA, an originally high-risk sample due to poverty that has been followed from birth into adulthood. Results of the exploratory factor analysis of the AAI state of mind ratings paralleled findings from large, normative risk samples (e.g., Haltigan et al., 
Table 6. Predicting AAI dimensions from the chronicity of childhood abuse/neglect experiences

\begin{tabular}{|c|c|c|c|c|c|c|}
\hline & \multicolumn{3}{|c|}{ AAI Dismissing } & \multicolumn{3}{|c|}{ AAI Preoccupied } \\
\hline & $\beta$ & $p$ & $R^{2}$ & $\beta$ & $p$ & $R^{2}$ \\
\hline 1. Abuse/neglect chronicity & 0.06 & .47 & .00 & 0.24 & $<.01$ & .06 \\
\hline 2. Abuse/neglect chronicity & 0.02 & .80 & .04 & 0.25 & $<.01$ & .15 \\
\hline Participant gender & -0.17 & .02 & & 0.22 & $<.01$ & \\
\hline Participant ethnicity & 0.05 & .48 & & -0.22 & $<.01$ & \\
\hline Maternal education & 0.01 & .96 & & -0.06 & .54 & \\
\hline Childhood SES & -0.09 & .37 & & 0.08 & .41 & \\
\hline 3. Abuse/neglect chronicity & 0.12 & .18 & .15 & 0.26 & $<.01$ & .23 \\
\hline Participant gender & -0.10 & .20 & & 0.17 & .02 & \\
\hline Participant ethnicity & -0.02 & .78 & & -0.20 & $<.01$ & \\
\hline Maternal education & -0.01 & .89 & & -0.06 & .52 & \\
\hline Childhood SES & -0.06 & .52 & & 0.05 & .58 & \\
\hline AAI dismissing & - & - & & -0.30 & $<.01$ & \\
\hline AAI preoccupied & -0.34 & $<.01$ & & - & - & \\
\hline
\end{tabular}

Note: $N=164$. AAI, Adult Attachment Interview; SES, socioeconomic status. For participant gender, $1=$ female, $0=$ male. For participant ethnicity, $1=$ White/non-Hispanic, $0=$ other. All models were significant at $p<.01$ except Model 1 and Model 2 for AAI dismissing ( $p=.47$ and .19 , respectively).

Table 7. Predicting AAI Dimensions from the number of childhood abuse/neglect subtypes

\begin{tabular}{|c|c|c|c|c|c|c|}
\hline & \multicolumn{3}{|c|}{ AAI Dismissing } & \multicolumn{3}{|c|}{ AAI Preoccupied } \\
\hline & $\beta$ & $p$ & $R^{2}$ & $\beta$ & $p$ & $R^{2}$ \\
\hline 1. No. of abuse/neglect subtypes & 0.02 & .86 & .00 & 0.23 & $<.01$ & .05 \\
\hline 2. No. of abuse/neglect subtypes & -0.03 & .74 & .04 & 0.24 & $<.01$ & .15 \\
\hline Participant gender & -0.18 & .02 & & 0.23 & $<.01$ & \\
\hline Participant ethnicity & 0.05 & .49 & & -0.22 & $<.01$ & \\
\hline Maternal education & -0.01 & .93 & & -0.07 & .48 & \\
\hline Childhood SES & -0.10 & .33 & & 0.06 & .52 & \\
\hline 3. No. of abuse/neglect subtypes & 0.06 & .52 & .13 & 0.23 & $<.01$ & .21 \\
\hline Participant gender & -0.10 & .19 & & 0.18 & .01 & \\
\hline Participant ethnicity & -0.02 & .82 & & -0.20 & $<.01$ & \\
\hline Maternal education & -0.03 & .76 & & -0.07 & .44 & \\
\hline Childhood SES & -0.08 & .42 & & 0.03 & .74 & \\
\hline AAI dismissing & - & - & & -0.30 & $<.01$ & \\
\hline AAI preoccupied & -0.33 & $<.01$ & & - & - & \\
\hline
\end{tabular}

Note: $N=164$. AAI, Adult Attachment Interview; SES, socioeconomic status. For participant gender, $1=$ female, $0=$ male. For participant ethnicity, $1=$ White/non-Hispanic, $0=$ other. All models were significant at $p<.01$ except Model 1 and Model 2 for AAI dismissing $(p=.86$ and .19 , respectively).

2014). Specifically, the state of mind scales loaded on two weakly correlated dimensions reflecting dismissing and preoccupied states of mind during the AAI. Moreover, the ratings of unresolved discourse loaded on the same factor as indicators of preoccupied states of mind, providing evidence that preoccupied and unresolved discourse during the AAI reflect a unitary psychological construct even within higher risk samples where these forms of insecurity are more prevalent.

Exploratory factor analyses of the CRI attachment state of mind ratings provided novel evidence regarding the factor structure of individual differences in adults' romantic attachment representations. Paralleling the AAI results, ratings that are traditionally used to differentiate between individuals with secure and dismissing romantic attachment states of mind loaded on one factor, whereas the ratings of adults' preoccupied and unresolved romantic attachment states of mind loaded on a second factor. Taken together, these findings indicate that variation in adults' discourse when discussing attachment-relevant experiences within their childhood caregiving relationships and their current romantic relationships are most parsimoniously captured by two modestly correlated dimensions reflecting dismissing and preoccupied states of mind. In combination with factor analytic findings related to infants' attachment behaviors (Fraley \& Spieker, 2003) and adults' self-reported thoughts, feelings, and behaviors within close relationships (Fraley \& Waller, 1998), these re- 
Table 8. Predicting AAI Dimensions from specific subtypes of childhood abuse and/or neglect experiences

\begin{tabular}{|c|c|c|c|c|c|c|}
\hline & \multicolumn{3}{|c|}{ AAI Dismissing } & \multicolumn{3}{|c|}{ AAI Preoccupied } \\
\hline & $\beta$ & $p$ & $R^{2}$ & $\beta$ & $p$ & $R^{2}$ \\
\hline 1. Neglect & 0.03 & .78 & .01 & -0.03 & .73 & .08 \\
\hline Sexual abuse & -0.07 & .41 & & 0.15 & .06 & \\
\hline Physical abuse & 0.04 & .69 & & 0.22 & $<.01$ & \\
\hline 2. Neglect & -0.04 & .70 & .04 & -0.02 & .86 & .17 \\
\hline Sexual abuse & -0.03 & .75 & & 0.12 & .13 & \\
\hline Physical abuse & 0.01 & .95 & & 0.24 & $<.01$ & \\
\hline Participant gender & -0.18 & .03 & & 0.23 & $<.01$ & \\
\hline Participant ethnicity & 0.06 & .48 & & -0.22 & $<.01$ & \\
\hline Maternal education & -0.01 & .91 & & -0.09 & .35 & \\
\hline Childhood SES & -0.10 & .31 & & 0.06 & .53 & \\
\hline 3. Neglect & -0.04 & .64 & .14 & -0.03 & .76 & .24 \\
\hline Sexual abuse & 0.02 & .84 & & 0.11 & .13 & \\
\hline Physical abuse & 0.09 & .30 & & 0.24 & $<.01$ & \\
\hline Participant gender & -0.10 & .21 & & 0.17 & .02 & \\
\hline Participant ethnicity & -0.02 & .80 & & -0.20 & $<.01$ & \\
\hline Maternal education & -0.04 & .67 & & -0.09 & .30 & \\
\hline Childhood SES & -0.08 & .40 & & 0.03 & .76 & \\
\hline AAI dismissing & - & - & & -0.30 & $<.01$ & \\
\hline AAI preoccupied & -0.34 & $<.01$ & & - & - & \\
\hline
\end{tabular}

Note: $N=164$. AAI, Adult Attachment Interview; SES, socioeconomic status. For participant gender, $1=$ female, $0=$ male. For participant ethnicity, $1=$ White/non-Hispanic, $0=$ other. All models were significant at $p<.01$ except Model 1 and Model 2 for AAI dismissing ( $p=.63$ and .18 , respectively).

sults provide additional evidence that this two-factor model may represent a more universal organization of individual differences in attachment-related cognition, affect, and behavior.

Although it was not a goal of the present study, the use of these dimensional assessments of adults' dismissing and preoccupied states of mind provided novel insights regarding the overlap between the representations of attachment captured by the AAI and the CRI. Prior analyses of the MLSRA data revealed nonsignificant concordance in adults' AAI and CRI classifications (Haydon et al., 2012). In contrast, the findings from the current study indicate that there are unique associations between adults' dismissing and preoccupied states of mind with regard to childhood caregivers and romantic partners that were being masked by the binary classifications of security versus insecurity used in Haydon et al. (2012). ${ }^{1}$ Specifically, dismissing states of mind during the

1. The results presented by Haydon et al. (2012) were based on CRI data from the age 20-21 assessment and AAI data from the age 19 assessment for the subset of MLSRA participants who completed the CRI at both ages (age 20-21 and age 26-28 years). Because our focus was on later AAI and CRI assessments, we examined the correlations among the dimensional measures of adults' dismissing and preoccupied states of mind for the earlier CRI and AAI assessments to serve as a sensitivity analysis, and the results did not differ from what is reported in the manuscript. Specifically, dismissing AAI states of mind were uniquely associated with dismissing CRI states of mind, and preoccupied AAI states of mind were uniquely associated with preoccupied CRI states of mind. These results indicate that differences in the findings reported in the current study and Haydon et al. (2012) are due to differences in how attachment (in)security was opera-
AAI were associated with dismissing (but not preoccupied) states of mind during the CRI, and AAI preoccupation was associated with preoccupied (but not dismissing) CRI states of mind. These kinds of findings illustrate how the dimensional assessments of dismissing and preoccupied states of mind can improve the potential of the AAI and CRI coding systems and allow researchers to identify unique and theoretically meaningful (e.g., Owens et al., 1995) correlates of adults' dismissing and preoccupied states of mind.

Of more importance, the current study represents the first prospective investigation of whether the consequences of childhood experiences of physical abuse, sexual abuse, and/ or neglect for attachment extend into adulthood. Individuals who experienced these subtypes of adverse caregiving, especially during multiple developmental periods, or when multiple subtypes were experienced, demonstrated more preoccupied states of mind during the AAI than nonabused/ neglected individuals in the MLSRA. Additional analyses of the specific subtypes and perpetrators indicated that individuals who experienced physical abuse or who experienced abuse perpetrated by a maternal or paternal figure were at greatest risk for developing more preoccupied AAI states of mind. The predictive significance of experiencing childhood abuse and/or neglect for adults' AAI states of mind was not accounted for by socioeconomic conditions or maternal edu-

tionally defined (namely, attachment dimensions vs. classifications) rather than developmental differences in the association between AAI and CRI states of mind. 
Table 9. Predicting AAI dimensions from childhood physical and/or sexual abuse perpetrator

\begin{tabular}{|c|c|c|c|c|c|c|}
\hline & \multicolumn{3}{|c|}{ AAI Dismissing } & \multicolumn{3}{|c|}{ AAI Preoccupied } \\
\hline & $\beta$ & $p$ & $R^{2}$ & $\beta$ & $p$ & $R^{2}$ \\
\hline 1. Paternal perpetrator & -0.07 & .44 & .01 & 0.28 & $<.01$ & .13 \\
\hline Maternal perpetrator & 0.07 & .36 & & 0.18 & .02 & \\
\hline Other perpetrator & -0.09 & .28 & & 0.01 & .87 & \\
\hline 2. Paternal perpetrator & -0.07 & .45 & .05 & 0.25 & $<.01$ & .23 \\
\hline Maternal perpetrator & 0.03 & .73 & & 0.22 & $<.01$ & \\
\hline Other perpetrator & -0.09 & .30 & & -0.01 & .99 & \\
\hline Participant gender & -0.17 & .03 & & 0.24 & $<.01$ & \\
\hline Participant ethnicity & 0.05 & .52 & & -0.22 & $<.01$ & \\
\hline Maternal education & -0.01 & .89 & & -0.06 & .54 & \\
\hline Childhood SES & -0.10 & .33 & & 0.06 & .51 & \\
\hline 3. Paternal perpetrator & 0.03 & .70 & .16 & 0.24 & $<.01$ & .29 \\
\hline Maternal perpetrator & 0.11 & .17 & & 0.23 & $<.01$ & \\
\hline Other perpetrator & -0.09 & .27 & & -0.03 & .72 & \\
\hline Participant gender & -0.08 & .27 & & 0.19 & $<.01$ & \\
\hline Participant ethnicity & -0.03 & .72 & & -0.20 & $<.01$ & \\
\hline Maternal education & -0.03 & .74 & & -0.06 & .49 & \\
\hline Childhood SES & -0.07 & .42 & & 0.03 & .73 & \\
\hline AAI dismissing & - & - & & -0.29 & $<.01$ & \\
\hline AAI preoccupied & -0.35 & $<.01$ & & - & - & \\
\hline
\end{tabular}

Note: $N=164$. AAI, Adult Attachment Interview; SES, socioeconomic status. For participant gender, $1=$ female, $0=$ male. For participant ethnicity, $1=$ White/non-Hispanic, $0=$ other. All models were significant at $p<.01$ except Model 1 and Model 2 for AAI dismissing ( $p=.47$ and .14 , respectively).

Table 10. Predicting CRI dimensions from childhood abuse/neglect status

\begin{tabular}{|c|c|c|c|c|c|c|}
\hline & \multicolumn{3}{|c|}{ CRI Dismissing } & \multicolumn{3}{|c|}{ CRI Preoccupied } \\
\hline & $\beta$ & $p$ & $R^{2}$ & $\beta$ & $p$ & $R^{2}$ \\
\hline 1. Abuse/neglect status & 0.17 & .07 & .03 & 0.12 & .22 & .01 \\
\hline 2. Abuse/neglect status & 0.14 & .15 & .08 & 0.15 & .15 & .05 \\
\hline Participant gender & -0.15 & .10 & & 0.18 & .05 & \\
\hline Participant ethnicity & -0.06 & .53 & & -0.04 & .69 & \\
\hline Maternal education & -0.17 & .13 & & 0.04 & .73 & \\
\hline Childhood SES & 0.02 & .86 & & 0.04 & .77 & \\
\hline 3. Abuse/neglect status & 0.12 & .24 & .11 & 0.12 & .23 & .09 \\
\hline Participant gender & -0.18 & .05 & & 0.20 & .02 & \\
\hline Participant ethnicity & -0.05 & .57 & & -0.03 & .77 & \\
\hline Maternal education & -0.18 & .11 & & 0.07 & .54 & \\
\hline Childhood SES & 0.01 & .90 & & 0.03 & .79 & \\
\hline CRI dismissing & - & - & & 0.18 & .05 & \\
\hline CRI preoccupied & 0.18 & .05 & & - & - & \\
\hline
\end{tabular}

Note: $N=116$. CRI, Current Relationship Interview; SES, socioeconomic status. For participant gender, $1=$ female, $0=$ male. For participant ethnicity, $1=$ White/non-Hispanic, $0=$ other. Model 3 for CRI dismissing was significant at $p<.05$ (Model 1 , $p=.07$; Model 2, $p=.05$ ). All models for CRI preoccupied were not statistically significant (Model 1, $p=.22$; Model 2, $p=.19$; Model, $p=.09$ ).

cation during childhood or participants' sex or ethnicity. In contrast, experiencing neglect per se during childhood was not uniquely associated with risk for either AAI preoccupied or dismissing states of mind.

These results thus replicate the findings reported by Roisman et al. (2017 [this issue]) that experiences of abuse perpetrated by a primary caregiver increase risk for preoccupied states of mind during adolescence. These convergent sets of findings are consistent with the idea that angry, passive, and unresolved discourse during the AAI reflect an attachment state of mind that is rooted in psychologically confusing, unpredictable, and potentially traumatic experiences within parent-child relationships (see Haydon et al., 2014, for findings based on more normative caregiving experiences). Moreover, the current study 
Table 11. Predicting CRI dimensions from the chronicity of childhood abuse/neglect experiences

\begin{tabular}{|c|c|c|c|c|c|c|}
\hline & \multicolumn{3}{|c|}{ CRI Dismissing } & \multicolumn{3}{|c|}{ CRI Preoccupied } \\
\hline & $\beta$ & $p$ & $R^{2}$ & $\beta$ & $p$ & $R^{2}$ \\
\hline 1. Abuse/neglect chronicity & 0.25 & $<.01$ & .06 & 0.11 & .24 & .01 \\
\hline 2. Abuse/neglect chronicity & 0.24 & .02 & .11 & 0.15 & .14 & .06 \\
\hline Participant gender & -0.16 & .08 & & .18 & .06 & \\
\hline Participant ethnicity & -0.07 & .43 & & -0.05 & .58 & \\
\hline Maternal education & -0.13 & .25 & & 0.05 & .66 & \\
\hline Childhood SES & 0.03 & .81 & & 0.03 & .79 & \\
\hline 3. Abuse/neglect chronicity & 0.22 & .03 & .13 & 0.11 & .29 & .08 \\
\hline Participant gender & -0.18 & .04 & & 0.20 & .03 & \\
\hline Participant ethnicity & -0.06 & .48 & & -0.04 & .67 & \\
\hline Maternal education & -0.14 & .22 & & 0.08 & .52 & \\
\hline Childhood SES & 0.02 & .85 & & 0.03 & .82 & \\
\hline CRI dismissing & - & - & & 0.17 & .06 & \\
\hline CRI preoccupied & 0.17 & .06 & & - & - & \\
\hline
\end{tabular}

Note: $N=116$. CRI, Current Relationship Interview; SES, socioeconomic status. For participant gender, $1=$ female, $0=$ male. For participant ethnicity, $1=$ White/non-Hispanic, $0=$ other. Model 1 and 3 for CRI dismissing were significant at $p<.05$ (Model 2 , $p=.06$ ). All models for CRI preoccupied were not statistically significant (Model 1, $p=.24$; Model 2, $p=.19$; Model 3, $p=.10$ ).

Table 12. Predicting CRI dimensions from the number of childhood abuse/neglect subtypes

\begin{tabular}{|c|c|c|c|c|c|c|}
\hline & \multicolumn{3}{|c|}{ CRI Dismissing } & \multicolumn{3}{|c|}{ CRI Preoccupied } \\
\hline & $\beta$ & $p$ & $R^{2}$ & $\beta$ & $p$ & $R^{2}$ \\
\hline 1. No. of abuse/neglect subtypes & 0.22 & .02 & .05 & 0.06 & .58 & .01 \\
\hline 2. No. of abuse/neglect subtypes & 0.20 & .04 & .10 & 0.07 & .50 & .04 \\
\hline Participant gender & -0.15 & .09 & & 0.18 & .05 & \\
\hline Participant ethnicity & -0.07 & .44 & & -0.05 & .57 & \\
\hline Maternal education & -0.15 & .18 & & 0.02 & .84 & \\
\hline Childhood SES & 0.01 & .92 & & 0.02 & .89 & \\
\hline 3. No. of abuse/neglect subtypes & 0.19 & .05 & .13 & 0.03 & .76 & .08 \\
\hline Participant gender & -0.19 & .04 & & 0.21 & .02 & \\
\hline Participant ethnicity & -0.06 & .50 & & -0.04 & .66 & \\
\hline Maternal education & -0.16 & .17 & & 0.05 & .65 & \\
\hline Childhood SES & 0.01 & .95 & & 0.01 & .91 & \\
\hline CRI dismissing & - & - & & 0.19 & .04 & \\
\hline CRI preoccupied & 0.18 & .04 & & - & - & \\
\hline
\end{tabular}

Note: $N=116$. CRI, Current Relationship Interview; SES, socioeconomic status. For participant gender, $1=$ female, $0=$ male. For participant ethnicity, $1=$ White/non-Hispanic, $0=$ other. Model 1 and 3 for CRI dismissing were significant at $p<.05$ (Model 2,p=.08). All models for CRI preoccupied were not statistically significant (Model 1, $p=.58$; Model 2, $p=.27$; Model 3, $p=.12$ ).

extends the findings from Roisman et al. (2017 [this issue]) by suggesting that the predictive significance of childhood experiences of abuse and/or neglect for preoccupied states of mind during the AAI may persist into adulthood.

In contrast to the findings from Roisman et al. (2017 [this issue]), associations between abuse and/or neglect experiences and dismissing AAI states of mind in the MLSRA generally were trivial in overall magnitude and consistently were not statistically significant. One possible explanation is that differences in research design or characteristics of the participants involved in the MLSRA and in the Roisman et al. (2017 [this issue]) study may have contributed to the differences in findings from the two studies. Alternatively, the con- sequences of abuse and neglect for dismissing AAI states of mind may be limited to adolescence and may not persist into adulthood. It is necessary to repeatedly collect AAI data across the transition from adolescence and adulthood in a sample with prospective information regarding childhood experiences of abuse and neglect in order to rigorously evaluate whether the predictive significance of childhood abuse and neglect for individuals' dismissing AAI states of mind in particular might fade over this transitional developmental period.

We also sought to extend the research in this area by investigating the predictive significance of specific forms of childhood abuse and neglect for adults' attachment-related representations of their romantic partners. In contrast to the 
Table 13. Predicting CRI dimensions from specific subtypes of childhood abuse and/or neglect experiences

\begin{tabular}{|c|c|c|c|c|c|c|}
\hline & \multicolumn{3}{|c|}{ CRI Dismissing } & \multicolumn{3}{|c|}{ CRI Preoccupied } \\
\hline & $\beta$ & $p$ & $R^{2}$ & $\beta$ & $p$ & $R^{2}$ \\
\hline 1. Neglect & 0.04 & .73 & .05 & -0.05 & .67 & .01 \\
\hline Sexual abuse & 0.07 & .45 & & 0.04 & .72 & \\
\hline Physical abuse & 0.17 & .11 & & 0.09 & .41 & \\
\hline 2. Neglect & -0.01 & .94 & .09 & -0.02 & .88 & .04 \\
\hline Sexual abuse & 0.12 & .24 & & 0.01 & .92 & \\
\hline Physical abuse & 0.14 & .18 & & 0.09 & .40 & \\
\hline Participant gender & -0.16 & .09 & & 0.19 & .04 & \\
\hline Participant ethnicity & -0.06 & .48 & & -0.04 & .64 & \\
\hline Maternal education & -0.17 & .14 & & 0.02 & .85 & \\
\hline Childhood SES & 0.01 & .99 & & 0.01 & .92 & \\
\hline 3. Neglect & 0.01 & .96 & .13 & -0.02 & .90 & .08 \\
\hline Sexual abuse & 0.11 & .24 & & -0.01 & .92 & \\
\hline Physical abuse & 0.13 & .23 & & 0.07 & .55 & \\
\hline Participant gender & -0.19 & .04 & & 0.21 & .02 & \\
\hline Participant ethnicity & -0.06 & .53 & & -0.03 & .72 & \\
\hline Maternal education & -0.17 & .13 & & 0.06 & .64 & \\
\hline Childhood SES & -0.01 & .97 & & 0.01 & .93 & \\
\hline CRI dismissing & - & - & & 0.19 & .04 & \\
\hline CRI preoccupied & 0.18 & .04 & & - & - & \\
\hline
\end{tabular}

Note: $N=116$. CRI, Current Relationship Interview; SES, socioeconomic status. For participant gender, $1=$ female, $0=$ male. For participant ethnicity, $1=$ White/non-Hispanic, $0=$ other. Model 3 for CRI dismissing was statistically significant at $p<.05$ (Model 1, $p=.25$; Model 2, $p=.08$ ). All models for CRI preoccupied were not statistically significant (Model 1, $p=.63$; Model 2, $p=.24 ;$ Model 3, $p=.11$ ).

Table 14. Predicting CRI dimensions from childhood physical and/or sexual abuse perpetrator

\begin{tabular}{|c|c|c|c|c|c|c|}
\hline & \multicolumn{3}{|c|}{ CRI Dismissing } & \multicolumn{3}{|c|}{ CRI Preoccupied } \\
\hline & $\beta$ & $p$ & $R^{2}$ & $\beta$ & $p$ & $R^{2}$ \\
\hline 1. Paternal perpetrator & 0.13 & .18 & .04 & 0.02 & .84 & .01 \\
\hline Maternal perpetrator & 0.14 & .16 & & 0.05 & .59 & \\
\hline Other perpetrator & -0.02 & .86 & & 0.05 & .62 & \\
\hline 2. Paternal perpetrator & 0.12 & .23 & .09 & 0.01 & .89 & .05 \\
\hline Maternal perpetrator & 0.11 & .26 & & 0.08 & .46 & \\
\hline Other perpetrator & -0.02 & .82 & & 0.06 & .57 & \\
\hline Participant gender & -0.14 & .12 & & 0.19 & .04 & \\
\hline Participant ethnicity & -0.06 & .49 & & -0.05 & .61 & \\
\hline Maternal education & -0.16 & .15 & & 0.02 & .86 & \\
\hline Childhood SES & -0.01 & .99 & & 0.02 & .85 & \\
\hline 3. Paternal perpetrator & 0.11 & .23 & .12 & -0.01 & .94 & .09 \\
\hline Maternal perpetrator & 0.10 & .31 & & 0.05 & .59 & \\
\hline Other perpetrator & -0.03 & .73 & & 0.06 & .53 & \\
\hline Participant gender & -0.17 & .05 & & 0.21 & .02 & \\
\hline Participant ethnicity & -0.05 & .54 & & -0.04 & .69 & \\
\hline Maternal education & -0.17 & .14 & & 0.05 & .66 & \\
\hline Childhood SES & -0.01 & .95 & & 0.02 & .85 & \\
\hline CRI dismissing & - & - & & 0.19 & .04 & \\
\hline CRI preoccupied & 0.18 & .04 & & - & - & \\
\hline
\end{tabular}

Note: $N=116$. CRI, Current Relationship Interview; SES, socioeconomic status. For participant gender, $1=$ female, $0=$ male. For participant ethnicity, $1=$ White/non-Hispanic, $0=$ other. Model 3 for CRI dismissing was statistically significant at $p<.05$ (Model 1, $p=.27$; Model 2, $p=.09$ ). All models for CRI preoccupied were not statistically significant (Model $1, p=.67$; Model 2, $p=.24$; Model 3, $p=.10$ ). 
results predicting AAI states of mind, experiencing more chronic abuse and/or neglect and experiencing multiple abuse and neglect subtypes were associated with risk for dismissing CRI states of mind. One possible explanation of the differential findings for adults' AAI and CRI states of mind is that experiencing childhood abuse and/or neglect increases the risk of both: (a) becoming preoccupied by (emotionally enmeshed in and psychologically confused by) one's adverse caregiving histories, likely because these experiences represent a serious violation of the normative expectations for caregiving relationships, and (b) adopting a defensive orientation toward romantic partners in adulthood, potentially as an effort to avoid experiencing similar hardships within these close, extrafamilial relationships. That said, associations between childhood abuse and neglect and CRI dismissing states of mind were less consistent across the various abuse and neglect parameters. In addition, several of the associations involving preoccupied CRI states of mind and childhood abuse and neglect were in the expected direction and were nontrivial in magnitude. Additional longitudinal research with larger samples is therefore needed to evaluate with greater statistical power the long-term predictive significance of childhood abuse and neglect for adults' romantic attachment representations.

Taken together, the present study provides the first prospective, longitudinal evidence that the harmful consequences of abuse and neglect for individuals' attachment outcomes are not limited to infancy and early childhood (e.g., Carlson, 1998; Carlson et al., 1989; Cyr et al., 2010; Egeland \& Sroufe, 1981) or even to adolescence (Roisman et al., 2017 [this issue]), but appear to extend into adulthood. At the same time, these findings build on research on the normative caregiving antecedents of individuals' attachment states of mind (e.g., Haydon et al., 2012, 2014) by suggesting that atypical caregiving experiences may also shape the development of adults' attachment-related representations. In light of these findings, a task for future research in this area will be to test whether adults' attachment states of mind represent a mechanism by which abuse and neglect during childhood undermine interpersonal functioning and mental health across the life course (e.g., Cicchetti, 2016; Egeland, Yates, Appleyard, \& Van Dulmen, 2002; Martin, Raby, et al., 2017; Norman et al., 2012; Thornberry \& Henry, 2013). In addition to testing theoretical ideas regarding the role of attachment representations in shaping individual adaptation (e.g., Bowlby, 1988), this research agenda could potentially yield insights into novel approaches for reducing the psychological and financial burden of childhood maltreatment (Gilbert et al., 2009).

Another question that is of interest to both basic and applied developmental scientists is whether the deleterious se-

\section{References}

Bailey, H. N., Moran, G., \& Pederson, D. R. (2007). Childhood maltreatment, complex trauma symptoms, and unresolved attachment in an at-risk sample of adolescent mothers. Attachment \& Human Development, 9, 139-161.

Barnett, D., Manly, J. T., \& Cicchetti, D. (1993). Defining child maltreatment: The interface between policy and research. In D. Cicchetti \& S. L. quelae of childhood abuse and neglect for adults' attachment representations can be offset by more supportive interpersonal experiences during the intervening years. There is converging evidence from longitudinal investigations into the (a) correlates of change in attachment security from infancy to young adulthood (Booth-LaForce, et al., 2014; Weinfield et al., 2004), (b) factors that disrupt the intergenerational transmission of abuse (Egeland, Jacobvitz, \& Sroufe, 1988; Merrick, Lee, \& Leeb, 2013), and (c) role of romantic relationships in particular as turning points in individual development (Salvatore, Haydon, Simpson, \& Collins, 2013) that suggests that relationships with alternative caregivers during childhood or adolescence or with romantic partners during adulthood can provide emotionally corrective opportunities for individuals with histories of childhood abuse and neglect.

The findings from this study underscore the value of evidence-based interventions that improve quality of parent-child relationships for maltreating and other high-risk families. There is a growing body of research demonstrating that parenting-focused interventions with at-risk families can reduce the prevalence of insecure and disorganized attachments during infancy and early childhood (Bernard, Dozier, Lindhiem, \& Carlson, 2012; Cicchetti, Rogosch, \& Toth, 2006; Suess, Bohlen, Carlson, Spangler, \& Frumentia Maier, in press). Based on the evidence of long-term associations between childhood experiences of abuse and neglect and adult attachment representations reported here, continued follow-up assessments of the families enrolled in these randomized control trials may provide evidence that the positive effects of these interventions persist even into adulthood. At the same time, studies of this nature would also greatly enhance causal inferences regarding the impact of childhood maltreatment experiences on later attachment states of mind. Although we statistically controlled for likely confounds in the present study, the predictive significance of childhood abuse and/or neglect could be at least partly attributable to other confounding variables that were not included in these analyses, such as genetic factors shared between parent-child pairs (e.g., Fearon, Shmueli-Goetz, Viding, Fonagy, \& Plomin, 2014).

In summary, the current investigation significantly advances our understanding of the factor structure and antecedents of adults' attachment states of mind. More generally, it highlights the value of methodological advances and studies with highrisk populations for testing attachment theory's foundational hypotheses. Continued research investments in these areas will help scholars to build on attachment theory's rich tradition of innovative and insightful research into the long-term significance of early parent-child relationships as well as the development of psychopathology across the life span.

Toth (Eds.), Child abuse, child development, and social policy (pp. 7 74). Norwood, NJ: Ablex.

Beckwith, L., Cohen, S. E., \& Hamilton, C. E. (1999). Maternal sensitivity during infancy and subsequent life events relate to attachment representation at early adulthood. Developmental Psychology, 35, 693-700. 
Bernard, K., Dozier, M., Bick, J., \& Carlson, E. (2012). Enhancing attachment organization among maltreated infants: Results of a randomized clinical trial. Child Development, 83, 623-636.

Berthelot, N., Ensink, K., Bernazzani, O., Normandin, L., Luyten, P., \& Fonagy, P. (2015). Intergenerational transmission of attachment in abused and neglected mothers: The role of trauma-specific reflective functioning. Infant Mental Health Journal, 36, 200-212.

Booth-LaForce, C., Groh, A. M., Burchinal, M. R., Roisman, G. I., Owen, M. T., \& Cox, M. J. (2014). Caregiving and contextual sources of continuity and change in attachment security from infancy to late adolescence. Monographs of the Society for Research in Child Development, 79(3, Serial No. 314), 67-84.

Bowlby, J. (1988). Developmental psychiatry comes of age. American Journal of Psychiatry, 145, 1-10.

Carlson, E. A. (1998). A prospective longitudinal study of attachment disorganization/disorientation. Child Development, 69, 1107-1128.

Carlson, V., Cicchetti, D., Barnett, D., \& Braunwald, K. (1989). Disorganized/disoriented attachment relationships in maltreated infants. Developmental Psychology, 25, 525-531.

Cicchetti, D. (1984). The emergence of developmental psychopathology. Child Development, 55, 1-7.

Cicchetti, D. (2016). Socioemotional, personality, and biological development: Illustrations from a multilevel developmental psychopathology perspective on child maltreatment. Annual Review of Psychology, 67, 187-211.

Cicchetti, D., Rogosch, F. A., \& Toth, S. L. (2006). Fostering secure attachment in infants in maltreating families through preventive interventions. Development and Psychopathology, 18, 623-649.

Cicchetti, D., \& Valentino, K. (2006). An ecological transactional perspective on child maltreatment: Failure of the average expectable environment and its influence upon child development. In D. Cicchetti \& D. J. Cohen (Eds.), Developmental psychopathology: Risk, disorder, and adaptation (Vol. 3, 2nd ed., pp. 129-201). Hoboken, NJ: Wiley.

Cloitre, M., Stovall McClough, C., Zorbas, P., \& Charuvastra, A. (2008). Attachment organization, emotion regulation, and expectations of support in a clinical sample of women with childhood abuse histories. Journal of Traumatic Stress, 21, 282-289.

Crowell, J. A., \& Owens, G. (1996). Current Relationship Interview and scoring system. Unpublished manuscript, State University of New York at Stony Brook.

Cyr, C., Euser, E. M., Bakemans-Kranenburg, M. J., \& van IJzendoorn, M. (2010). Attachment security and disorganization in maltreating and highrisk families: A series of meta-analyses. Development and Psychopathology, 22, 87-108.

Egeland, B., Jacobvitz, D., \& Sroufe, L. A. (1988). Breaking the cycle of abuse. Child Development, 59, 1080-1088.

Egeland, B., \& Sroufe, L. A. (1981). Maltreatment and early attachment. Child Development, 52, 44-52.

Egeland, B., Yates, T., Appleyard, K., \& Van Dulmen, M. (2002). The longterm consequences of maltreatment in the early years: A developmental pathway model to antisocial behavior. Children's Services: Social Policy, Research, and Practice, 5, 249-260.

Fabrigar, L. R., Wegener, D. T., MacCallum, R. C., \& Strahan, E. J. (1999). Evaluating the use of exploratory factor analysis in psychological research. Psychological Methods, 4, 272-299.

Fearon, P., Shmueli-Goetz, Y., Viding, E., Fonagy, P., \& Plomin, R. (2014). Genetic and environmental influences on adolescent attachment. Journal of Child Psychology and Psychiatry, and Allied Disciplines, 55, 1033-1041.

Fraley, R. C., \& Spieker, S. J. (2003). Are infant attachment patterns continuously or categorically distributed? A taxometric analysis of Strange Situation behavior. Developmental Psychology, 39, 387-404.

Fraley, R. C., \& Waller, N. G. (1998). Adult attachment patterns: A test of the typological model. In J. A. Simpson \& W. S. Rholes (Eds.), Attachment theory and close relationships (pp. 77-114). New York: Guilford Press.

Gilbert, R., Widom, C. S., Browne, K., Fergusson, D., Webb, E., \& Janson, S. (2009). Burden and consequences of child maltreatment in high-income countries. Lancet, 373, 68-81.

Graham, J. W (2009). Missing data analysis: Making it work in the real world. Annual Review of Psychology, 60, 549-576.

Greenhoot, A. F. (2011). Retrospective methods in developmental science. In B. Laursen, T. D. Little, \& N. A. Card (Eds.), Handbook of developmental research methods (pp. 196-210). New York: Guilford Press.

Grossmann, K. E., Grossmann, K., \& Kindler, H. (2006). Early care and the roots of attachment and partnership representations. In K. E. Grossmann,
K. Grossmann, \& E. Waters (Eds.), Attachment from infancy to adulthood: The major longitudinal studies (pp. 223-244). New York: Guilford Press.

Haltigan, J. D., Roisman, G. I., \& Haydon, K. C. (2014). The latent structure of the Adult Attachment Interview: Exploratory and confirmatory evidence. Monographs of the Society for Research in Child Development, 79(3, Serial No. 314), 15-35.

Haydon, K. C., Collins, W. A., Salvatore, J. E., Simpson, J. A., \& Roisman, G. I. (2012). Shared and distinctive origins and correlates of adult attachment representations: The developmental organization of romantic functioning. Child Development, 83, 1689-1702.

Haydon, K. C., Roisman, G. I., Owen, M. T., Booth-LaForce, C., \& Cox, M. J. (2014). Shared and distinctive antecedents of Adult Attachment Interview state-of-mind and inferred-experience dimensions. Monographs of the Society for Research in Child Development, 79(3, Serial No. 314), $108-125$.

Hesse, E. (2008). The Adult Attachment Interview: Protocol, method of analysis, and empirical studies. In J. Cassidy \& P. R. Shaver (Eds.), Handbook of attachment: Theory, research, and clinical applications (2nd ed., pp. 552-598). New York: Guilford Press.

Hughes, P., Turton, P., Hopper, E., McGauley, G. A., \& Fonagy, P. (2004). Factors associated with the unresolved classification of the Adult Attachment Interview in women who have suffered stillbirth. Development and Psychopathology, 16, 215-230.

Jacobvitz, D., Leon, K., \& Hazen, N. (2006). Does expectant mothers' unresolved trauma predict frightened/frightening maternal behavior? Risk and protective factors. Development and Psychopathology, 18, 363-379.

Leeb, R. T., Paulozzi, L., Melanson, C., Simon, T., \& Arias, I. (2008). Child maltreatment surveillance: Uniform definitions for public health and recommended data elements, Version 1.0. Atlanta, GA: Centers for Disease Control and Prevention and National Center for Injury Prevention and Control.

Lyons-Ruth, K., Yellin, C., Melnick, S., \& Atwood, G. (2003). Childhood experiences of trauma and loss have different relations to maternal unresolved and hostile-helpless states of mind on the AAI. Attachment \& $\mathrm{Hu}$ man Development, 5, 330-352.

Macfie, J., Swan, S. A., Fitzpatrick, K. L., Watkins, C. D., \& Rivas, E. M. (2014). Mothers with borderline personality and their young children: Adult attachment interviews, mother-child interactions, and children's narrative representations. Development and Psychopathology, 26, 539551.

Madigan, S., Vaillancourt, K., McKibbon, A., \& Benoit, D. (2012). The reporting of maltreatment experiences during the Adult Attachment Interview in a sample of pregnant adolescents. Attachment \& Human Development, 14, 119-143.

Main, M., \& Goldwyn, R. (1998). Adult attachment scoring and classification system. Unpublished manuscript, University of California, Berkeley.

Martin, J., Bureau, J.-F., Lafontaine, M.-F., Cloutier, P. F., Hsiao, C., Pallanca, D., \& Meinz, P. (2017). Preoccupied but not dismissing attachment states of mind are associated with nonsuicidal self-injury. Development and Psychopathology, 29, 379-388.

Martin, J., Raby, K. L., Labella, M. H., \& Roisman, G. I. (2017). Childhood abuse and neglect, attachment states of mind, and non-suicidal self-injury. Manuscript submitted for publication.

Merrick, M. T., Lee, R. D., \& Leeb, R. T. (2013). Examining the role of safe, stable, and nurturing relationships in the intergenerational continuity of child maltreatment: Introduction to the special issue. Journal of Adolescent Health, 53, S1-S3.

Muthén, L. K., \& Muthén, B. O. (1998-2015). Mplus user's guide (7th ed.) Los Angeles: Author.

Narayan, A. J., Englund, M. M., \& Egeland, B. (2013). Developmental timing and continuity of exposure to interparental violence and externalizing behavior as prospective predictors of dating violence. Development and Psychopathology, 25, 973-990.

National Scientific Council on the Developing Child. (2012). The science of neglect: The persistent absence of responsive care disrupts the developing brain: Working Paper 12. Retrieved from http://www.developingchild.harvard.edu

Norman, R. E., Byambaa, M., De, R., Butchart, A., Scott, J., \& Vos, T. (2012). The long-term health consequences of child physical abuse, emotional abuse, and neglect: A systematic review and meta-analysis. PLOS Medicine, 9, e1001349.

Owens, G., Crowell, J., Pan, H., Treboux, D., O’Connor, E., \& Waters, E. (1995). The prototype hypothesis and the origins of attachment working 
models: Adult relationships with parents and romantic partners, Monographs of the Society for Research in Child Development, 60(2-3, Serial No. 244), 216-233.

Pierrehumbert, B., Torrisi, R., Glatz, N., Dimitrova, N., Heinrichs, M., \& Halfon, O. (2009). The influence of attachment on perceived stress and cortisol response to acute stress in women sexually abused in childhood or adolescence. Psychoneuroendocrinology, 34, 924-938.

Raby, K. L., Cicchetti, D., Carlson, E. A., Egeland, B., \& Collins, W. A. (2013). Genetic contributions to continuity and change in attachment security: A prospective, longitudinal investigation from infancy to young adulthood. Journal of Child Psychiatry and Psychology, 54, 1223-1230.

Raby, K. L., Roisman, G. I., Simpson, J. A., Collins, W. A., \& Steele, R. D. (2015). Greater maternal insensitivity in childhood predicts greater electrodermal reactivity during conflict discussions with romantic partners in adulthood. Psychological Science, 26, 348-353.

Rajecki, P., Lamb, M., \& Obmascher, P. (1978). Toward a general theory of infantile attachment: A comparative review of aspects of the social bond. Behavioral and Brain Sciences, 3, 417-464.

Riggs, S. A., \& Jacobvitz, D. (2002). Expectant parents' representations of early attachment relationships: Associations with mental health and family history. Journal of Consulting and Clinical Psychology, 70, 195-204.

Roisman, G. I., Fraley, R. C., \& Belsky, J. (2007). A taxometric study of the Adult Attachment Interview. Developmental Psychology, 43, 675-686.

Roisman, G. I., Fraley, R. C., \& Booth-LaForce, C. (2014). Pulling ourselves up by our bootstraps: A rejoinder to van IJzendoorn and Bakermans-Kranenburg (2014). Monographs of the Society for Research in Child Development, 79(3, Serial No. 314), 168-173.

Roisman, G. I., Madsen, S. D., Hennighausen, K. H., Sroufe, L. A., \& Collins, W. A. (2001). The coherence of dyadic behavior across parent-child and romantic relationships as mediated by the internalized representation of experience. Attachment \& Human Development, 3, 156-172.

Roisman, G. I., Rogosch, F. A., Cicchetti, D., Groh, A. M., Haltigan, J. D., Haydon, K. C., . . Steele, R. D. (2017). Attachment states of mind and inferred childhood experiences in maltreated and comparison adolescents from low-income families. Development and Psychopathology, 29, 337-345.

Salvatore, J., Haydon, K. C., Simpson, J. A., \& Collins, W. C. (2013). The distinctive role of romantic relationships in moderating the effects of early caregiving on adult anxious-depressed symptoms over 9 years. Development and Psychopathology, 25, 843-856.

Shaffer, A., Huston, L., \& Egeland, B. (2008). Identification of child maltreatment using prospective and self-report methodologies: A comparison of maltreatment incidence and relation to later psychopathology. Child Abuse \& Neglect, 32, 682-692.

Sroufe, L. A. (1990). Considering normal and abnormal together: The essence of developmental psychopathology. Development and Psychopathology, 2, 335-348.

Sroufe, L. A., Egeland, B., Carlson, E. A., \& Collins, W. A. (2005). The development of the person: The Minnesota Study of Risk and Adaptation from Birth to Adulthood. New York: Guilford Press.
Stalker, C. A., \& Davies, F. (1998). Working models of attachment and representations of the object in a clinical sample of sexually abused women Bulletin of the Menninger Clinic, 62, 334-350.

Stevens, G., \& Featherman, D. L. (1981). A revised socioeconomic index of occupational status. Social Science Research, 10, 364-395.

Stoltenborgh, M., van IJzendoorn, M. H., Euser, E. M., \& Bakermans-Kranenburg, M. J. (2011). A global perspective on child sexual abuse: Meta-analysis of prevalence around the world. Child Maltreatment, 16, 79-101.

Stovall-McClough, K. C., \& Cloitre, M. (2006). Unresolved attachment, PTSD, and dissociation in women with childhood abuse histories. Journal of Consulting and Clinical Psychology, 74, 219-228.

Suess, G. J., Bohlen, U., Carlson, E. A., Spangler, G., \& Frumentia Maier, M. (in press). Effectiveness of attachment based STEEP ${ }^{\mathrm{TM}}$ intervention in a German high-risk sample. Attachment \& Human Development.

Taylor-Seehafer, M., Jacobvitz, D., \& Steiker, L. H. (2008). Patterns of attachment organization, social connectedness, and substance use in a sample of older homeless adolescents-Preliminary findings. Family \& Community Health, 31, S81-S88.

Thornberry, T. P., \& Henry, K. L. (2013). Intergenerational continuity in maltreatment. Journal of Abnormal Child Psychology, 41, 555-569.

Van Hoof, M.-J., Van Lang, N. D. J., Speekenbrink, S., van IJzendoorn, M. H., \& Vermeiren, R. R. J. M. (2015). Adult Attachment Interview differentiates adolescents with childhood sexual abuse from those with clinical depression and non-clinical controls. Attachment \& Human Development, 17, 354-375.

van IJzendoorn, M. H., \& Bakermans-Kranenburg, M. J. (2014). Confined question for continuity: The categorical versus continuous nature of attachment. Monographs of the Society for Research in Child Development, 79(3, Serial No. 314), 157-167.

Waldinger, R. J., Cohen, S., Schultz, M. S., \& Crowell, J. A. (2015). Security of attachment to spouses in late life: Concurrent and prospective links with cognitive and emotional well-being. Clinical Psychological Science, 3, 516-529.

Weinfield, N. S., Sroufe, L. A., \& Egeland, B. (2000). Attachment from infancy to early adulthood in a high-risk sample: Continuity, discontinuity, and their correlates. Child Development, 71, 695-702.

Weinfield, N. S., Whaley, G. J. L, \& Egeland, B. (2004). Continuity, discontinuity, and coherence in attachment from infancy to late adolescence: Sequelae of organization and disorganization. Attachment \& Human Development, 6, 73-97.

Widom, C. S., Raphael, K. G., \& DuMont, K. A. (2004). The case for prospective longitudinal studies in child maltreatment research: Commentary on Dube, Williamson, Thompson, Felitti, and Anda (2004). Child Abuse \& Neglect, 28, 715-722.

Zajac, K., \& Kobak, R. (2009). Caregiver unresolved loss and abuse and child behavior problems: Intergenerational effects in a high-risk sample. Development and Psychopathology, 21, 173-187. 